\title{
The Influence of Physician-Rating Websites on Patient Physician Preference
}

\author{
Ajith Malige, MD, Kristofer S. Matullo, MD \\ Department of Orthopaedic Surgery, St. Luke’s University Hospital, Bethlehem, PA, USA
}

Background: Physician-rating websites (PRWs) are designed to publicly report physician quality information while bringing forth a sense of transparency. This study looks to identify the influence PRWs have on a patient's choice of orthopedic hand surgeon while stratifying patient physician preference by various demographic characteristics.

Methods: This survey-based study was conducted in a suburban outpatient orthopedic hand practice. All patients between 18 to 89 years of age who presented for an appointment were asked to participate. Survey questions aimed to identify patient demographics and the sources patients used to choose their hand surgeon.

Results: Overall, 104 patients completed our survey. Our study population was predominantly between 51 and 70 years of age $(50.0 \%)$, women $(60.6 \%)$, and Caucasian $(84.6 \%)$, received a general education degree or high school diploma (36.5\%), was employed $(49.0 \%)$, and owned private health insurance $(59.6 \%)$. One hundred and two patients $(98.1 \%)$ answered that their physician's reputation is important. Seventy-five patients $(72.1 \%)$ reported that they heard about their surgeon by physician referral, while only two (1.9\%) used online search engines. Sixty-six patients $(63.5 \%)$ noted that physician referrals were most trustworthy. Only 10 patients (9.6\%) consulted PRWs to choose their surgeon, most of whom were younger than 50 years $(n=6)$, Caucasian $(n=$ 8), and employed ( $n=7)$ and had schooling after high school $(n=8)$.

Conclusions: Despite increases in digital information exchange platforms, PRWs are not commonly used by suburban orthopedic hand patients to exchange information about or choose their hand surgeon. Patients still primarily rely on physician referrals and word of mouth from family and friends to choose their surgeon.

Keywords: Physician, Rating, Website, Orthopaedic, Hand

The last two decades have been marked by the explosion of the digital age, with the Internet and social media slowly creeping into the constantly evolving field of health care. Since public reporting systems were implemented in the mid-1980s, physician-rating websites (PRWs) have quickly grown in number and popularity. ${ }^{1,2)}$ This platform, designed to publicly report patient-perceived quality of physicians, brings forth a sense of transparency, holding physicians responsible for their quality of care and deci-

Received July 8, 2019; Accepted August 5, 2019

Correspondence to: Ajith Malige, MD

Department of Orthopaedic Surgery, St. Luke's University Hospital, 801

Ostrum St, Bethlehem, PA 18015, USA

Tel: +1-484-526-1735, Fax: +1-484-526-1593

E-mail: ajith.malige@gmail.com sion making. ${ }^{3)}$ This exchange of information brings to light any discrepancies in quality among various providers, allowing patients to make a more informed choice about their physicians. ${ }^{4-6)}$

Despite this plethora of information on multiple PRWs including RateMDs, Vitals, and ZocDoc, previous studies have noted the overall low rates of PRW use by patients. Emmert et al. ${ }^{7)}$ noted that $32 \%$ of patients in Germany were aware of German PRWs while only $25 \%$ of patients were actually using these websites. ${ }^{8-10)}$ This brings to question whether PRWs and online search engines are substantially influencing patient decision making when choosing a physician or whether patients still rely mostly on other channels, such as doctor referrals and word of mouth. This study looks to identify the influence PRWs have on a patient's choice of orthopedic surgeon while 
stratifying patient physician preference by various demographic characteristics. We hope this information will aid orthopaedic surgeons in better reaching out to their patient population while furthering their own practice.

\section{METHODS}

This study has been approved by St. Luke's University Health Network Institutional Review Board. This surveybased study was conducted in a suburban Orthopedic Department outpatient setting. All patients between the ages of 18 to 89 years who presented for an appointment with their hand surgeon were asked to fill out a paper survey (Supplementary Material 1), whether they were new patients or established. Participants were not given any financial or other incentives to participate. Patients who refused to participate in the study were not handed a survey to complete.

The first set of questions recorded demographic information such as patient age, sex, employment status, education status, and income level. The second set of questions inquired about the channels a patient used to hear of and choose their physician as well as the importance they placed on PRWs. This included questions about their usage of online sources to find their surgeon, how often they post physician ratings online, and whether they were aware of their hand surgeon's rating online.

Data were catalogued by using a password-protected electronic spreadsheet. Data were analyzed with simple descriptive statistics. After consulting with our statistician, we decided the small number of patients in each demographic category precludes the use of statistical analysis to determine associations in this data set.

\section{RESULTS}

Overall, 104 patients over a 3-month period verbally consented to participate in the study and filled out our survey. All surveys, whether or not they were answered in completion, were included. Demographic breakdown of our study population is summarized in Table 1. Our study population was predominantly between the ages of 51 and 70 years $(\mathrm{n}=52,50.0 \%)$, women $(\mathrm{n}=63,60.6 \%)$, and Caucasian $(\mathrm{n}=88,84.6 \%)$. The highest number of patients reported stopping schooling after receiving a general education degree, high school diploma, or associate degree (n $=69,66.3 \%)$, being currently employed $(n=51,49.0 \%)$, and owning health insurance through a private company (n $=62,59.6 \%)$. Most patients also reported driving less than 25 miles $(\mathrm{n}=90,86.5 \%)$ to arrive at their appointment at the orthopedic clinic.

A total of 102 patients (98.1\%) answered that the reputation of their physician was important to them. Sev-

Table 1. Demographic Breakdown of Sample Patient Population

\begin{tabular}{|lcccc|}
\hline Variable & Caucasian Hispanic & $\begin{array}{c}\text { Otherl } \\
\text { did not } \\
\text { respond }\end{array}$ & Total \\
\hline Sex & 34 & 4 & 2 & 40 \\
\hline Male & 54 & 5 & 4 & 63 \\
\hline Female & 0 & 1 & 0 & 1 \\
\hline Did not respond & & & & \\
\hline Age (yr) & 9 & 4 & 0 & 13 \\
\hline$\leq 30$ & 15 & 3 & 1 & 19 \\
\hline $31-50$ & 46 & 3 & 3 & 52 \\
\hline $51-70$ & 18 & 0 & 2 & 20 \\
\hline$\geq 71$ & 0 & 0 & 0 & 0 \\
\hline Did not respond & & & & \\
\hline
\end{tabular}

Employed

\begin{tabular}{lrrrr} 
Yes & 45 & 5 & 1 & 51 \\
\hline No & 6 & 3 & 0 & 9 \\
\hline Disabled & 6 & 1 & 1 & 8 \\
\hline Retired & 31 & 1 & 4 & 36 \\
\hline Did not respond & 0 & 0 & 0 & 0
\end{tabular}

Education

\begin{tabular}{|lcccr|}
\hline No high school degree & 3 & 0 & 0 & 3 \\
\hline High school/GED & 33 & 3 & 2 & 38 \\
\hline College/associate's degree & 24 & 6 & 1 & 31 \\
\hline Bachelor's degree or higher & 26 & 1 & 2 & 29 \\
\hline Did not respond & 2 & 0 & 1 & 3 \\
\hline
\end{tabular}

Health insurance

\begin{tabular}{lrrrr} 
Private insurance & 55 & 5 & 2 & 62 \\
\hline Medicare & 28 & 2 & 4 & 34 \\
\hline Medicaid & 4 & 2 & 0 & 6 \\
\hline No insurance & 1 & 1 & 0 & 2 \\
\hline Did not respond & 0 & 0 & 0 & 0 \\
\hline Total surveyed & 88 & 10 & 6 & 104 \\
\hline
\end{tabular}

GED: general education degree. 
enty-five patients (72.1\%) reported that they heard about their hand surgeon through their primary care physician or another physician's referral. Twenty patients (19.2\%) reported hearing about their hand surgeon through family and friend referrals while only two patients (1.9\%) used online search engines (both patients were men older than
50 years with an education past high school). When asked what mode of referral was most trustworthy, 66 patients (63.5\%) noted that other physician referrals were most trustworthy and 24 patients (23.1\%) noted that family or friend referrals were most trustworthy, while two patients (1.9\%) noted online search engines as the source of in-

Table 2. Survey Answers Based on Demographic Breakdown

\begin{tabular}{|c|c|c|c|c|c|c|c|c|c|}
\hline \multirow[b]{2}{*}{ Variable } & \multirow{2}{*}{$\begin{array}{l}\text { Total } \\
\text { survey }\end{array}$} & \multicolumn{4}{|c|}{ How did you hear about your physician? } & \multicolumn{4}{|c|}{ Which method of referral do you trust the most? } \\
\hline & & PCP & $\begin{array}{l}\text { Family/ } \\
\text { friend }\end{array}$ & Online & $\begin{array}{l}\text { Multiple } \\
\text { source }\end{array}$ & PCP & $\begin{array}{l}\text { Family/ } \\
\text { friend }\end{array}$ & Online & $\begin{array}{l}\text { Multiple } \\
\text { source }\end{array}$ \\
\hline \multicolumn{10}{|l|}{ Age (yr) } \\
\hline$<30$ & 13 & $10(76.9)$ & $3(23.1)$ & 0 & 0 & $9(69.2)$ & $3(23.1)$ & 0 & $1(7.7)$ \\
\hline $31-50$ & 19 & $14(73.7)$ & $5(26.3)$ & 0 & 0 & $10(52.6)$ & $7(36.8)$ & 0 & $2(10.5)$ \\
\hline $51-70$ & 52 & $38(73.1)$ & $9(17.3)$ & $1(1.9)$ & $2(3.8)$ & $32(61.5)$ & $11(21.2)$ & 2 (3.8) & $5(9.6)$ \\
\hline$\geq 71$ & 20 & $13(65.0)$ & $3(15.0)$ & $1(5.0)$ & $1(5.0)$ & $15(75.0)$ & $3(15.0)$ & 0 & $2(10.0)$ \\
\hline \multicolumn{10}{|l|}{ Sex } \\
\hline Male & 40 & 33 (82.5) & $2(5.0)$ & $2(5.0)$ & $2(5.0)$ & $28(70.0)$ & $5(12.5)$ & $1(2.5)$ & $5(12.5)$ \\
\hline Female & 60 & 41 (68.3) & $18(30.0)$ & 0 & $1(1.7)$ & 38 (38.3) & $19(31.7)$ & $1(1.7)$ & $4(6.7)$ \\
\hline Did not respond & 1 & $1(100)$ & 0 & 0 & 0 & 0 & 0 & 0 & $1(100)$ \\
\hline \multicolumn{10}{|l|}{ Employment status } \\
\hline Employed & 51 & $36(70.6)$ & $12(23.5)$ & $1(2.0)$ & $1(2.0)$ & $30(58.8)$ & $12(23.5)$ & $1(2.0)$ & $6(9.8)$ \\
\hline Not employed & 9 & $8(88.9)$ & $1(11.1)$ & 0 & 0 & $5(55.6)$ & $3(33.3)$ & 0 & $1(11.1)$ \\
\hline Disabled & 8 & $5(62.5)$ & $2(25.0)$ & 0 & 0 & $6(75.0)$ & $2(25.0)$ & 0 & 0 \\
\hline Retired & 36 & $26(72.2)$ & $5(13.9)$ & $1(2.8)$ & $2(5.6)$ & $25(69.4)$ & $7(19.4)$ & $1(2.8)$ & $3(8.3)$ \\
\hline \multicolumn{10}{|l|}{ Education } \\
\hline No HS degree & 3 & $3(100)$ & 0 & 0 & 0 & $3(100)$ & 0 & 0 & 0 \\
\hline HS/Assoc degree & 69 & $50(72.5)$ & 12 (17.4) & $2(2.9)$ & $2(2.9)$ & $43(62.3)$ & 16 (23.2) & $2(2.9)$ & $6(8.9)$ \\
\hline Bach/Grad degree & 29 & $19(65.5)$ & $8(27.6)$ & 0 & $1(3.4)$ & 18 (62.1) & $7(24.1)$ & 0 & $4(13.8)$ \\
\hline Did not respond & 3 & $3(100)$ & 0 & 0 & 0 & $2(66.7)$ & $1(33.3)$ & 0 & 0 \\
\hline \multicolumn{10}{|l|}{ Health insurance } \\
\hline Medicare/Medicaid & 40 & $28(70.0)$ & $6(15.0)$ & $1(2.5)$ & $2(5.0)$ & $27(67.5)$ & $9(22.5)$ & $1(2.5)$ & $3(7.5)$ \\
\hline Private insurance & 62 & $45(72.6)$ & 14 (22.6) & $1(1.6)$ & $1(1.6)$ & $37(59.7)$ & $15(24.2)$ & $1(1.6)$ & $7(11.3)$ \\
\hline None & 2 & $2(100)$ & 0 & 0 & 0 & $2(100)$ & 0 & 0 & 0 \\
\hline Total survey answer & 104 & 75 & 20 & 2 & 3 & 66 & 24 & 2 & 10 \\
\hline
\end{tabular}

Values are presented as number (\%). Survey answers to the questions "How did you hear about your physician" and "Which method of referral do you trust the most" based on demographics (age, gender, employment status, education, and insurance); absolute number of responses and percentage of each demographic category that answered each choice. All responses not reported above were left blank by participant.

PCP: primary care physician, No HS degree: did not finish high school, HS/Assoc degree: high school or associate degree, Bach/Grad degree: Bachelor's or graduate degree. 
formation they trust the most. These were the same two patients who used online search engines to find their hand surgeon (Table 2).

Only 10 patients (9.6\%) admitted to consulting a physician rating website to research the reputation of their hand surgeon, while only 46 patients (44.2\%) were able to provide the online rating they used to choose their hand surgeon (average answered rating of 9.46/10). Twenty-six percent of patients between 31 and 50 years of age consulted a PRW, the highest rate among any age group, and $7.7 \%$ of patients younger than 30 years and between 51 and 70 years also consulted PRWs. Overall, $17.5 \%$ of men,

Table 3. Survey Answers Based on Demographic Breakdown

\begin{tabular}{|c|c|c|c|c|c|c|c|c|}
\hline \multirow[t]{2}{*}{ Variable } & \multirow[t]{2}{*}{$\begin{array}{l}\text { Total } \\
\text { survey }\end{array}$} & \multicolumn{2}{|c|}{$\begin{array}{l}\text { Is the reputation of a } \\
\text { physician important to } \\
\text { you? }\end{array}$} & \multicolumn{2}{|c|}{$\begin{array}{l}\text { Did you consult a PRW prior } \\
\text { to choosing physician? }\end{array}$} & \multicolumn{3}{|c|}{$\begin{array}{l}\text { How much do you } \\
\text { believe online ratings? }\end{array}$} \\
\hline & & Yes & No & Yes & No & Not at all & Somewhat & Fully believe \\
\hline \multicolumn{9}{|l|}{ Age (yr) } \\
\hline$<30$ & 13 & $13(100.0)$ & 0 & $1(7.7)$ & $11(84.6)$ & $2(15.4)$ & $8(61.5)$ & $1(7.7)$ \\
\hline $31-50$ & 19 & $19(100.0)$ & 0 & $5(26.3)$ & $14(73.7)$ & $2(10.5)$ & $16(84.2)$ & 0 \\
\hline $51-70$ & 52 & $50(96.2)$ & $1(1.9)$ & $4(7.7)$ & $45(86.5)$ & $6(11.5)$ & $39(75.0)$ & $1(1.9)$ \\
\hline$\geq 71$ & 20 & $20(100.0)$ & 0 & 0 & $19(95.0)$ & $5(25.0)$ & $12(60.0)$ & $1(1.0)$ \\
\hline \multicolumn{9}{|l|}{ Sex } \\
\hline Male & 40 & $40(100.0)$ & 0 & $7(17.5)$ & $30(75.0)$ & $6(15.0)$ & $25(62.5)$ & $2(1.9)$ \\
\hline Female & 60 & $61(96.8)$ & $1(1.6)$ & $3(4.8)$ & 58 (92.1) & $9(14.3)$ & 49 (77.8) & $1(1.6)$ \\
\hline Did not respond & 1 & $1(100.0)$ & 0 & 0 & $1(100)$ & 0 & $1(100)$ & 0 \\
\hline \multicolumn{9}{|l|}{ Employment status } \\
\hline Employed & 51 & $49(96.1)$ & $1(2.0)$ & $7(13.7)$ & $42(82.4)$ & $5(9.8)$ & 40 (78.4) & $1(2.0)$ \\
\hline Not employed & 9 & $9(100.0)$ & 0 & $1(11.1)$ & $8(88.9)$ & $1(11.1)$ & $7(77.8)$ & $1(1.0)$ \\
\hline Disabled & 8 & $8(100.0)$ & 0 & $1(12.5)$ & $7(87.5)$ & $3(37.5)$ & $5(62.5)$ & 0 \\
\hline Retired & 36 & $36(100.0)$ & 0 & $1(2.8)$ & 32 (88.9) & $6(16.7)$ & 23 (63.9) & $1(2.8)$ \\
\hline \multicolumn{9}{|l|}{ Education } \\
\hline No HS degree & 3 & $3(100.0)$ & 0 & 0 & $3(100)$ & 0 & $3(100)$ & 0 \\
\hline HS/Assoc degree & 69 & $67(97.1)$ & $1(1.4)$ & $5(7.2)$ & $60(87.0)$ & $12(17.4)$ & $45(65.2)$ & $3(4.3)$ \\
\hline Bach/Grad degree & 29 & $29(100.0)$ & 0 & $4(13.8)$ & 24 (82.8) & $3(10.3)$ & $25(86.2)$ & 0 \\
\hline Did not respond & 3 & $3(100.0)$ & 0 & $1(33.3)$ & $2(66.7)$ & 0 & $2(66.7)$ & 0 \\
\hline \multicolumn{9}{|l|}{ Health insurance } \\
\hline Medicare/Medicaid & 40 & $40(100.0)$ & 0 & $1(2.5)$ & $37(92.5)$ & $9(22.5)$ & $27(67.5)$ & $1(2.5)$ \\
\hline Private insurance & 62 & $60(96.8)$ & $1(1.6)$ & $9(14.5)$ & 50 (80.6) & $6(9.7)$ & 46 (74.2) & $2(3.2)$ \\
\hline None & 2 & $2(100.0)$ & 0 & 0 & $2(100)$ & 0 & $2(100)$ & 0 \\
\hline Total survey answer & 104 & 102 & 1 & 10 & 89 & 15 & 75 & 3 \\
\hline
\end{tabular}

Values are presented as number (\%). Survey answers to the questions "Is the reputation of a physician important to you," "Did you consult a PRW to research the reputation of your physician prior to your appointment," and "How much do you believe online ratings" based on demographics (age, gender, employment status, education, and insurance); absolute number of responses and percentage of each demographic category that answered each choice. All responses not reported above were left blank by participant.

PRW: physician-rating website, No HS degree: did not finish high school, HS/Assoc degree: high school or associate degree, Bach/Grad degree: bachelor's or graduate degree. 
$13.7 \%$ of employed patients, $13.8 \%$ of patients who have a bachelor's or graduate degree, and $14.5 \%$ of patients with private insurance also consulted a PRW.

Seventy-five patients (72.1\%) noted that they "some- what" believe online ratings, while 85 patients $(81.7 \%)$ noted that online comments on physician rating websites matter more than an absolute physician grading scale (Table 3). However, 88 patients $(84.6 \%)$ noted that they

\section{Table 4. Survey Answers Based on Demographic Breakdown}

\begin{tabular}{|c|c|c|c|c|c|c|c|c|c|}
\hline \multirow[t]{2}{*}{ Variable } & \multirow[t]{2}{*}{$\begin{array}{l}\text { Total } \\
\text { survey }\end{array}$} & \multicolumn{3}{|c|}{$\begin{array}{l}\text { What matters more to you, online } \\
\text { grading scales or comments? }\end{array}$} & \multicolumn{3}{|c|}{$\begin{array}{c}\text { How many physician ratings have } \\
\text { you posted online? }\end{array}$} & \multicolumn{2}{|c|}{$\begin{array}{c}\text { If you found out your } \\
\text { physician's online rating was } \\
\text { poor, would you cancel your } \\
\text { appointment? }\end{array}$} \\
\hline & & Scale & Comment & Both & 0 & $1-5$ & $11+$ & Yes & No \\
\hline \multicolumn{10}{|l|}{ Age (yr) } \\
\hline$<30$ & 13 & $2(15.4)$ & $9(69.2)$ & $1(7.7)$ & $11(84.6)$ & 0 & $1(7.7)$ & $1(7.7)$ & 11 (84.6) \\
\hline $31-50$ & 19 & $1(5.3)$ & 17 (89.5) & 0 & $15(78.9)$ & $4(21.1)$ & 0 & $7(36.8)$ & $10(52.6)$ \\
\hline $51-70$ & 52 & 0 & 43 (82.7) & $1(1.9)$ & 43 (82.7) & $5(9.6)$ & 0 & 15 (28.8) & $29(55.8)$ \\
\hline$\geq 71$ & 20 & $1(5.0)$ & $12(60.0)$ & 0 & $19(95.0)$ & 0 & 0 & $8(40.0)$ & $8(40.0)$ \\
\hline \multicolumn{10}{|l|}{ Sex } \\
\hline Male & 40 & $4(10.0)$ & $29(72.5)$ & $1(2.5)$ & $32(80.0)$ & $4(10.0)$ & $1(2.5)$ & $9(22.5)$ & $25(62.5)$ \\
\hline Female & 60 & 0 & 51 (81.0) & $1(1.6)$ & 55 (87.3) & $5(7.9)$ & 0 & $22(34.9)$ & 32 (50.8) \\
\hline Did not respond & 1 & 0 & $1(100)$ & 0 & $1(100)$ & 0 & 0 & 0 & $1(100)$ \\
\hline \multicolumn{10}{|l|}{ Employment status } \\
\hline Employed & 51 & $1(2.0)$ & 43 (84.3) & $1(2.0)$ & $40(78.4)$ & $8(15.7)$ & $1(2.0)$ & $12(23.5)$ & $33(64.7)$ \\
\hline Not employed & 9 & $2(22.2)$ & $7(77.8)$ & 0 & $9(100)$ & 0 & 0 & $2(22.2)$ & $6(66.7)$ \\
\hline Disabled & 8 & 0 & $7(87.5)$ & 0 & $7(87.5)$ & 0 & 0 & $3(37.5)$ & 3 (37.5) \\
\hline Retired & 36 & $1(2.8)$ & $24(66.7)$ & $1(2.8)$ & 32 (88.9) & $1(2.8)$ & 0 & 14 (38.9) & $16(44.4)$ \\
\hline \multicolumn{10}{|l|}{ Education } \\
\hline No HS degree & 3 & $1(33.3)$ & $1(33.3)$ & 0 & $3(100)$ & 0 & 0 & $1(33.3)$ & $2(66.7)$ \\
\hline HS/Assoc degree & 69 & $3(4.3)$ & $52(75.3)$ & $2(2.9)$ & 58 (84.1) & $5(7.2)$ & $1(1.4)$ & $20(29.0)$ & $35(50.7)$ \\
\hline Bach/Grad degree & 29 & 0 & $26(89.7)$ & 0 & $25(86.2)$ & $3(10.3)$ & 0 & $10(34.5)$ & $18(62.1)$ \\
\hline Did not respond & 3 & 0 & $2(66.7)$ & 0 & $2(66.7)$ & $1(33.3)$ & 0 & 0 & $3(100.0)$ \\
\hline \multicolumn{10}{|l|}{ Health insurance } \\
\hline Medicare/Medicaid & 40 & $1(2.5)$ & $28(70.0)$ & $1(2.5)$ & $36(90.0)$ & $1(2.5)$ & 0 & 15 (37.5) & $19(47.5)$ \\
\hline Private insurance & 62 & $3(4.8)$ & $51(82.3)$ & $1(1.6)$ & $50(80.6)$ & $8(12.9)$ & $1(1.6)$ & $14(22.6)$ & $39(62.9)$ \\
\hline None & 2 & 0 & $2(100)$ & 0 & $2(100)$ & 0 & 0 & $2(100)$ & 0 \\
\hline Total survey answers & 104 & 4 & 81 & 2 & 88 & 9 & 1 & 31 & 58 \\
\hline
\end{tabular}

Values are presented as number (\%). Survey answers to the questions "What matters more to you, online grading scales or comments," "How many physician ratings have you posted online," and "If you found out your physician's online rating was poor, would you cancel your appointment" based on demographics (age, gender, employment status, education, and insurance); absolute number of responses and percentage of each demographic category that answered each choice. All responses not reported above were left blank by participant. No participant answered that they have posted 6-10 physician ratings online.

No HS degree: did not finish high school, HS/Assoc degree: high school or associate degree, Bach/Grad degree: bachelor's or graduate degree. 
have never posted a physician rating online. Overall, $21.1 \%$ of patients between 31 and 50 years of age, $10 \%$ of men, $15.7 \%$ of employed patients, $10.3 \%$ of patients with a bachelor's or graduate degree, and $12.9 \%$ of patients with private insurance did respond that they have posted between 1 to 5 posts online about physicians. Furthermore, 58 patients $(55.8 \%)$ noted that they would not cancel their appointment if they found out their physician's online rating was poor. Overall, $84.6 \%$ of patients younger than 30 years, $62.5 \%$ of men, $64.7 \%$ of employed and $66.7 \%$ of unemployed patients, $66.7 \%$ of patients who did not complete high school and $62.1 \%$ of those with a bachelor's or graduate degree, and $62.9 \%$ of patients with private insurance shared this sentiment (Table 4).

\section{DISCUSSION}

This survey-based study aimed to identify the orthopedic hand patient population's most trusted sources of physician referral as well as their knowledge and use of physician rating websites. The growth of the internet has allowed patients the opportunity to easily share information, ratings, and recommendations regarding multiple physicians. PRWs allow patients to present a combination of subjective comments and ratings with a numerical scale in various categories, including bedside manner, medical knowledge, accessibility, personality traits, and wait times to present a detailed evaluation about their physician. This revolutionizing platform potentially represents a more comprehensive and encompassing source for patients to make an educated decision about their desired orthopedic hand surgeon.

Our results suggest that patients highly value their physician's reputation (98\%); thus, a reliable source of information about their various physician options is instrumental in their decision making. However, despite internet sources containing an endless amount of information on physicians and their practice, $72.1 \%$ of our sample patient population noted that they heard about their hand surgeon through a physician referral, and $63.5 \%$ of patients noted that they trust other physician referrals the most. Online search engines were still rarely used to find a physician (1.9\%), with no one under the age of 50 years consulting online sources to choose a hand surgeon. Furthermore, $84.6 \%$ of patients have never posted ratings on PRWs, and only $9.6 \%$ of patients consulted PRWs when making their physician choice. These figures are much lower than those reported by Emmert et al. ${ }^{7}$ : they found $25 \%$ of patients were using PRWs in Germany.

However, a higher percentage of younger patients, compared to older patients, reported consulting PRWs. A higher percentage of patients who received higher education past high school also used PRWs more frequently than those who did not receive an education past high school, leading the authors to believe that the use of PRWs might increase in the future, especially as social media and the digital age continue to grow.

The older population, who did not grow up with the current level of internet usage, might be resistant to PRWs and other online sources of information, instead relying heavily on older methods of referrals, including other physicians' referrals and word of mouth from family members or friends. We believe that this could be in part because they prefer the personal nature of these reviews from someone they are comfortable with and trust rather than basing their decision off a website with evaluations from relative strangers. Orthopedic hand surgeons must be cognizant of this fact when they aim to expand their practice, targeting strong relationships with other physicians and urging existing patients to spread the word about their practice in order to increase patient volume. However, as the younger population who grew up during the digital age grows older and constitutes a higher percentage of the patient population, the trend could shift towards higher PRW use, a trend that orthopedic hand surgeons should also keep current on when trying to expand their practice. Furthermore, the results presented here from our suburban setting might be different from those in a sample population based out of rural or urban settings.

Among the patients who did consult PRWs, the participating orthopedic hand surgeon's average rating was answered as $9.46 / 10$, bringing up the possibility that this high rating was positively influencing the small percentage of patients who did consult PRWs to choose this surgeon. The opposite scenario must be considered as well, in which patients view an artificially low online rating posted by a small number of biased patients, bringing into question how accurate these ratings truly are. The value of PRWs increases only when multiple ratings are posted to counteract any outliers and bring the overall rating closer to its true value. Patient preference in using PRWs can also be affected by region and health care system, while the ratings physicians get can be affected by their peers in the same health care system. Most patients only "somewhat" believe online PRWs and ratings, probably because very few patients spend the time to post feedback about their hand surgeon, a trend that was also observed in our sample population. We believe that the hypothesized future increase in PRWs is centered around an increase in patient posting as well, which will allow patients to truly evaluate 
potential physicians online without worrying about overarching bias. Our survey did not, however, query about which specific websites a patient viewed or referred to online, bringing up the possibility that certain PRWs were more influential than others in our sample cohort. However, this preference might not be consistent worldwide because patients with different backgrounds in different locations might be drawn to different PRWs. Finally, the younger population reported that they would not cancel their appointment even if their physician's online rating was poor because either they do not trust PRWs or they trust their referral source more than comments from other patients. Other demographic categories had approximately equal response frequencies for this question.

Our study has a few limitations, some inherent to a survey-based study. Our study population is mostly Caucasian, women, and older than 51 years, characteristics that define the local patient population but not necessarily the entire orthopedic hand population. Survey-based studies also allow for recall bias, potentially inaccurate answering due to lack of trust of anonymity of answers and responder fatigue towards the end of the survey. Only patients who agreed to fill out the survey were included in the study, making this a convenience sample. What was not considered are those patients who refused to complete the survey and those who did not make appointments with our hand surgeon, possibly owing to information present on PRWs. This survey was also conducted in a specialty orthopedic clinic instead of a general orthopedic clinic. Furthermore, this study provides descriptive statistics without statistical analysis, precluding the need for a power analysis. After consulting with our statisticians, we decided the small demographic subcategories present in our sample make the likelihood of type II error high, because of which we only reported descriptive statistics instead of the chi-square and Fischer exact testing that would ordinarily be used to analyze this categorical data. Further studies should aim to include a wider variety of patient population, a larger sample cohort, and statistical analysis of survey responses in order to determine any statistical differences between patient preferences. It would also be interesting to compare multiple PRWs and their reviews on physicians to identify any differences in review patterns.

\section{CONFLICT OF INTEREST}

Kristofer S. Matullo, MD, is a consultant for DePuy Synthes, Integra Life Sciences. No other potential conflicts of interest relevant to this article were reported.

\section{ACKNOWLEDGEMENTS}

The abstract has been presented as a poster in the American Association of Hand Surgery 2017 Annual Meeting, Waikoloa, Hawaii (January 10, 2017-January 14, 2017).

\section{SUPPLEMENTARY MATERIAL}

Supplementary Material is available on the electronic version of this paper at the CiOS website, www.ecios.org.

\section{REFERENCES}

1. Hannan EL, Kilburn H Jr, Racz M, Shields E, Chassin MR. Improving the outcomes of coronary artery bypass surgery in New York State. JAMA. 1994;271(10):761-6.

2. Gao GG, McCullough JS, Agarwal R, Jha AK. A changing landscape of physician quality reporting: analysis of patients' online ratings of their physicians over a 5-year period. J Med Internet Res. 2012;14(1):e38.

3. Lagu T, Hannon NS, Rothberg MB, Lindenauer PK. Patients' evaluations of health care providers in the era of social networking: an analysis of physician-rating websites. J Gen Intern Med. 2010;25(9):942-6.

4. Dynan L, Goudie A, Smith RB, Fairbrother G, Simpson LA. Differences in quality of care among non-safety-net, safetynet, and children's hospitals. Pediatrics. 2013;131(2):304-11.

5. Hibbard JH. What can we say about the impact of public reporting? Inconsistent execution yields variable results. Ann
Intern Med. 2008;148(2):160-1.

6. Lebrun LA, Shi L, Zhu J, et al. Racial/ethnic differences in clinical quality performance among health centers. J Ambul Care Manage. 2013;36(1):24-34.

7. Emmert M, Meier F, Pisch F, Sander U. Physician choice making and characteristics associated with using physicianrating websites: cross-sectional study. J Med Internet Res. 2013;15(8):e187.

8. RateMDs. Search over 2 million doctor ratings and reviews [Internet]. RateMDs; 2004 [cited 2020 Jan 10]. Available from: https://www.ratemds.com/.

9. Vitals. Hand surgery-orthopaedic surgery [Internet]. Vitals; 2020 [cited 2020 Jan 10]. Available from: https://www.vitals. com.

10. Oliver Kharraz. Orthopaedic surgeon [Internet]. Zocdoc; 2007 [cited 2020 Jan 10]. Available from: https://www.zocdoc.com/. 